\title{
OS SETENTA ANOS DA ASSOCIAÇÃO BRASILEIRA DE ENFERMAGEM (ABEn)
}

\author{
THE BRAZILIAN NURSING ASSOCIATION (ABEN) SEVENTIETH ANNIUERSARY
}

\author{
Isabel dos Reis Silva Oliveira ${ }^{1}$ \\ Ivete Santos Barreto ${ }^{2}$ \\ Maria Goreti de Lima ${ }^{1}$
}

\begin{abstract}
RESUMO: Os setenta anos da existência da Associação Brasileira de Enfermagem, antes Associação Brasileira de Enfermeiras Diplomadas, representam, na verdade, setenta anos da história da Enfermagem no Brasil. Constatamos, numa retrospectiva histórica, que a criação da entidade; a sua organização que passa por várias mudanças, adaptando-se às exigências impostas pelas conjunturas; os marcos culturais, onde se destacam a Revista Brasileira de Enfermagem, Semana Brasileira de Enfermagem, Seminário Nacional de Pesquisa em Enfermagem, os Encontros Regionais de Enfermagem e o Congresso Brasileiro de Enfermagem, são demonstrações da força e garra desta entidade que sobrevive das lutas, conquistas e realizações da categoria. Destacamos o avanço político a partir das duas últimas décadas na organização estrutural e política, o processo decisório mais democrático internamente e externamente (Conselho Nacional da ABEn): uma expressão política social autônoma enquanto sociedade civil, maior entrosamento com outras entidades nacional $e$ internacional. Por fim, relacionamos os desafios que se apresentam para a atual gestão de entidade.
\end{abstract}

UNITERMOS: Retrospectiva histórica - Avanço político na organização Democratização.

ABSTRACT: The celebration of the Brazilian Nursing Association seventieth anniversary, former Brazilian Graduated Nurses Association, represents, in fact, seventy years of the history of Nursing in Brazil. We have certified, in a historical retrospective that the entity's creation, its organization which has been through several changes, adapting itself to the demands imposed by the conjunctures; the cultural landmarks, where the Brazilian Nursing Magazine, Brazilian Nursing Week, National Seminar of Research in Nursing, the Nursing Regional Meetings and the Brazilian Congress of Nursing are highlighted and are a demonstration of power and guts of this entity that survives from the struggle, conquests and achievements for the category. We also highlight the political advance these last two decades for the political and structural organization, the more democratic decisory process both internal and externally (ABEn's National Council); an autonomous social and political expression while civil society, better relationship with other national and international entities. Finally, we relate the challenges which appear to the entity's present management.

KEYWORDS: Historical retrospective - Organization political advance Democratization.

\footnotetext{
${ }^{1}$ Enfermeira da FHDF - Diretora da ABEn Nacional.

${ }^{2}$ Enfermeira da UFG - Diretora da ABEn Nacional.
} 


\section{INTRODUÇÃO}

Antes de contar a história da criação da Associação Brasileira de Enfermagem (ABEn), falaremos da organização associativa do(a) enfermeiro(a), tendo como escopo o entendimento de que as ações das entidades que representam a categoria, isoladas ou coletivamente, expressam sua organização de forma global, plena, seja no campo cientifico cultural (ABEn), trabalhista (Federação Nacional dos Enfermeiros/FNE) ou disciplinar do exercício profissional (Conselho Federal de Enfermagem/COFEN). Todas se complementam, permitindo a realização do objetivo maior das entidades, abordando o conjunto do exercício e da prática profissional da enfermagem: o desenvolvimento do seu conhecimento teórico, a defesa de seus interesses e a regulamentação de seu exercicio profissional.

A existência de diversas entidades com finalidades distintas encontra respaldo na legislação vigente. O objetivo, entretanto, deveria ser único: a formação de uma moral homogênea entre os profissionais. O "perfil do profissional ideal" ou as concepções de mundo e das relações sociais (o individuo / cidadão / profissional) mostram nitidamente uma das concepções centrais das sociedades capitalistas, relações sociais fundamentais na fragmentação dos indivíduos, na "separação dos homens em indivíduos isolados ou/não em classes". Percebemos também que a separação de finalidades e objetivos entre as entidades contribui para a segregação e alienação do trabalhador sobre a importância do seu próprio trabalho. Em geral, ele associa-se apenas ao sindicato por não compreender a importância da sua organização profissional e pelo entendimento de que o Sindicato buscará sua segurança econômica - reforçando a dicotomia existente entre luta econômica e capacitação profissional.

Durante o governo militar, a repressão política criou obstáculos para a sindicalização no Brasil, e as associações assumiram muitas vezes a luta trabalhista - com a ABEn não foi diferente. Assim é que, no final dos anos 70 , os enfermeiros se reuniram para pensar uma nova intervenção nos rumos da entidade, denominada esta iniciativa "Movimento Participação" Ele visava conscientizar todos que a ABEn é uma entidade defensora dos direitos individuais e coletivos de seus associados e da sociedade, iniciando uma reflexão sobre o processo da enfermagem na saúde, utilizando para isso os seus eventos e a sua prática quotidiana- a ABEn passa a refletir, apoiar e encaminhar lutas em conjunto com as entidades de enfermagem e da saúde, tendo uma participação mais efetiva nos fóruns de discussão nacional do desenvolvimento do sistema de saúde e da Enfermagem Brasileira. 


\section{OBJETIVOS}

1. Elaborar uma retrospectiva histórica da ABEn, destacando a evolução estrutural e organizacional, os marcos culturais, as relações internacionais, as lutas, as vitórias, as realizações e os desafios atuais.

2. Sistematizar os dados encontrados de forma a elaborar um texto próprio para divulgar a ABEn, com base em conteúdos históricos, junto aos alunos de diferentes niveis de enfermagem e aos profissionais de serviço.

\section{METODOLOGIA}

O estudo foi realizado com base em referencial bibliográfico, documentos históricos existentes na sede da ABEn-Nacional em Brasília. Com o objetivo de facilitar a compreensão do trabalho, os conteúdos foram divididos e agrupados de acordo com a sua evolução estrutural e organizacional.

\section{A Criação}

No dia 12 de agosto de 1926 deu-se o primeiro passo organizacional da luta da enfermagem brasileira: foi criada a Associação Brasileira de Enfermagem durante o governo de Artur da Silva Bernardes. Seu primeiro nome foi Associação Brasileira de Enfermeiras Diplomadas. Era o primeiro reflexo da chegada da enfermagem "moderna" em nosso pais, centrada no modelo americano e seguindo as orientações normativas do Conselho Internacional de Enfermeiros/CIE (estatuto, organização, funcionamento). Não houve, entretanto, nenhuma discussão sobre suas diretrizes políticas que pudessem subsidiar as relações de trabalho da diretoria com a "categoria", com as entidades internacionais, com o governo e com a sociedade.

Do berço, a Associação traz a essência do corporativismo e a intensificação da divisão do trabalho em enfermagem, separando as "verdadeiras" enfermeiras e os profissionais ocupacionais. Traz ainda em seu bojo a aliança histórica da enfermagem com as classes dominantes. A relação estreita com o Governo faziam as reivindicações serem atendidas com mais facilidade. Inicialmente, eram admitidas como sócias da entidade apenas as enfermeiras diplomadas por Escolas.

Pode-se considerar que, neste primeiro momento, os principais objetivos da Associação eram:

1. Lutar pelo desenvolvimento da enfermagem no Brasil.

2. Apropriação de todo campo do conhecimento da enfermagem pelo enfermeiro.

3. Fortalecimento de um espírito de corpo, privilegiando o status social e cultural. 


\section{Fundadoras}

A convicção de que uma profissão para se desenvolver necessita de uma associação levou, em 1926, as pioneiras, ex-alunas da Escola Ana Neri, a "ousarem", dentro de suas "concepções ideológicas", dar início ao projeto da ABEn. Eram elas: Maria Francisca de Almeida Reis, Remidia Bandeira de Sousa Gayoso, Judith Arêas, Isolina Lossio, Isaura Barbosa Lima, Odete Seabra, Cecy Clause e Heloisa Veloso.

\section{Designativos}

Inicialmente a entidade denominou-se Associação Nacional de Enfermeiras Diplomadas (ANED). Em 1929, passou a chamar-se Associação Nacional de Enfermeiras Diplomadas Brasileiras (ANEDB).

Em 1944, houve uma alteração no estatuto e a palavra "nacional" foi retirada, atendendo solicitação do Ministério do Trabalho. $O$ nome da entidade simplificou-se para Associação Brasileira de Enfermeiras Diplomadas (ABED).

Em 1953, por sugestão da Presidente da ABED, Glete de Alcântara, foi aprovada a mudança do nome para Associação Brasileira de Enfermagem $(A B E n)$, que permanece até os dias atuais.

\section{Organização}

Em 1926 foi eleita uma diretoria provisória, constituida por Remidia Bandeira de Sousa Gayoso (Presidente); Isolina Lossio (Secretária) e Isaura Barbosa de Lima (Tesoureira), que dirigiu a entidade até 1927, quando a Diretoria foi escolhida por eleição indireta, em Assembléia de Enfermeiros. A gestão durou de 1927 a 1938, com a seguinte composição: Edith de Magalhães Fraenkel (Presidente); Heloisa Veloso ( $1^{\text {a }}$ Secretária); Maria Francisca de Almeida Reis ( $1^{\text {a }}$ Tesoureira); em 1929 foram acrescidos à Diretoria os cargos de VicePresidente, $2^{\mathrm{a}}$ Secretária e Conselho Fiscal, conforme registro de "Anayde Correia de Carvalho". Na diretoria de 1938 são acrescidos mais dois cargos, o de $2^{a}$ Tesoureira e o de Bibliotecária, surgindo, como plano de trabalho, a criação das Comissões Permanentes que, segundo Hilda A. Krisch, dariam "oportunidade a outros sócios de trabalharem para a Associação. Inicialmente foi criada a Comissão Permanente de Educação e Legislação, de caráter permanente, continuando como Comissão até 1993. Com a ampliação do plano, foram sendo criadas outras comissões, algumas com durações transitórias: Informações e Publicidade (1944/1955); Intercâmbio Cultural e Profissional (1946/1963), Assistência (1955/1963).

Com a reformulação estatutária ocorrida em 1993 foi alterada a composição da Diretoria com as comissões sendo transformadas em diretorias: de Educação; Científico- Cultural; de Assuntos Profissionais; de Publicações e Comunicação Social; do Centro de Estudos e Pesquisas em Enfermagem (CEPEn). 


\section{Órgãos Deliberativos}

Eles foram criados para apoiar a entidade nas relações com seus associados, descentralizando o poder da Diretoria. São os seguintes órgãos deliberativos criados na estrutura da ABEn:

\section{Comissão Consultiva}

Foi criada em 1944, composta por sete membros, sendo integrada por representantes de órgãos públicos como SESP e DASP. Sua finalidade era colaborar no encaminhamento de demandas, que exigiam soluções concretas e imediatas, destacando-se:

1. Sindicato dos Enfermeiros, que se encontrava nas mãos dos práticos (1943),

2. Salários dos enfermeiros;

3. Criação do Conselho de Enfermagem;

4. Concurso Público - aberto pelo Departamento de Administração de Pessoal do Serviço Público (DASP).

\section{Conselho Deliberativo (1946/1958)}

A história não detalha o trabalho desenvolvido por este Conselho, segundo Oliveira, 1990, "salvo quando refere à competência do mesmo para aprovar anualmente $o$ relatório da Diretoria e a constituição das Comissões Permanentes, assim como o trabalho de apreciação de documentos elaborados pela Comissão de Regimento". Ele era composto pelos membros da Diretoria, Conselho Fiscal, Presidente das Seções, redatora da Revista Anais de Enfermagem, diretoras das Divisões e quatro membros associados, eleitos pela Assembléia Geral

\section{Conselho Nacional da ABEn}

Na reforma do estatuto da ABEn, em 1986, foi criado o Conselho Nacional da $A B E n / C O N A B E n$ (órgão deliberativo e intermediário entre as Assembléias de Delegados e a Diretoria da ABEn). O CONABEn é constituído pelos presidentes das Seções e integrantes da Diretoria Nacional. Foi implementado pela primeira diretoria eleita pelo "Movimento Participação" com o intuito de efetivar uma prática de trabalho democrático entre as diretorias nacionais e das seções. É nessa instância que são traçadas as diretrizes políticas de trabalho da ABEn. $O$ Conselho reúne-se ordinariamente duas vezes por ano ou extraordinariamente quando necessário.

\section{Assembléia Geral}

Foi instituída, em 1929, com o nome de Assembléia Geral Ordinária, passando a chamar-se Assembléia de Delegados em 1965. A partir de 1988 foi denominada Assembléia Nacional de Delegados (AND), como órgão máximo de deliberação da entidade, responsável pelo estabelecimento das diretrizes 
necessárias ao cumprimento de suas finalidades. É constituída de delegados natos (membros da Diretoria Nacional, Presidentes das Seções e Regionais) e delegados eleitos nas Seções (sócios efetivos) A AND reúne-se em Sessão Ordinária uma vez por ano por convocação do presidente da ABEn Nacional, ou em sessão extraordinária quando necessário (Estatuto da $A B E n$, art 46). As deliberações específicas das Seções são realizadas em Assembléia Geral da Seção (AGS) e, no âmbito Regional, pela Assembléia Geral Regional (AGR).

\section{Seções}

Em 1945, iniciou-se o processo de descentralização da ABED, com a criação da "Associação de Enfermeiras Diplomadas de São Paulo", e do "Núcleo do Distrito Federal", em 1946, seguindo-se a da Amazônia (Amazonas, Pará, Maranhão e Território do Norte) e, sucessivamente, seções congêneres nos demais estados. A Seção corresponde à Unidade da Federação e constitui a base da organização e a estrutura da entidade. No periodo de 1945 a 1979 foram instaladas 22 Seções da ABEn, 23 Regionais e um núcleo em todo o pais

(Anexo I).

\section{Estatuto}

A Associação estruturou-se no período de 1928/1943. Quando solicita da sua filiação ao Conselho Internacional de Enfermeiros (CIE), a entidade teve de adaptar-se às exigências do órgão internacional. Até o final de 1928, a entidade permaneceu funcionando em caráter informal, quando foi elaborado e aprovado o primeiro e definitivo estatuto, publicado no Diário Oficial de 5 de maio de 1929.

O Estatuto é o instrumento norteador da organização, filosofia, objetivos e estrutura da entidade. Na tentativa de adequar a entidade às necessidades de seus associados e de impulsionar seu crescimento político, o estatuto da ABEn de 1926/1995 passou por sete reformulações. Em 1975, destaca-se a inclusão dos técnicos de enfermagem no quadro de sócios e, em 1976, em Assembléia de Delegados extraordinária, realizada no XXVIII CBEn, deliberou-se sobre a criação do sócio especial para incluir os estudantes do último ano do curso de graduação.

O atual estatuto foi reformulado e aprovado em sessão extraordinária da Assembléia Nacional de Delegados, por ocasião do $46^{\circ} \mathrm{CBEn}$, Porto Alegre-RS.

\section{Patrimônio}

É constituído de bens móveis e imóveis e o acervo histórico documental da ABEn, que possui um terreno na llha do Governador, que se destina à construção da casa do Enfermeiro, e a sede da ABEn Nacional, situada à SGA Norte, Quadra 603, Conjunto "B", Brasília-DF, em terreno doado pela Novacap em 1958. 


\section{Marcos Culturais}

Foram construídos ao longo dos anos, permanecendo como tradição da vida associativa; destacam-se:

\section{Revista Brasileira de Enfermagem (REBEn)}

Foi criada em 20 de maio de 1932 com a denominação de "Anais de Enfermagem", tendo seus direitos autorais registrados em 1934. Em 1954 passou a ser denominada "Revista Brasileira de Enfermagem". É um dos órgãos oficiais de divulgação da Associação Brasileira de Enfermagem e tem por finalidade divulgar a produção das diferentes áreas do saber de interesse da enfermagem, visando o desenvolvimento técnico-científico e cultural da profissão. Com periodicidade trimestral, a revista publica matérias inéditas, sob a forma de artigos, de resultados de pesquisa, de atualização e de opinião. Coordenada pela Diretora de Publicações e Comunicação Social da ABEn, a revista publica trabalhos selecionados pelo seu Conselho Editorial, composto por pesquisadores de renome científico, mantendo uma grande preocupação com a qualidade da revista. Hoje, $80 \%$ dos seus trabalhos são fruto de investigação científica. Segundo Araújo, 1995, "Nesses 63 anos de existência, a história da REBEn tem sido marcada por inúmeras dificuldades, mas também pela tenacidade e esforço, não só de seus editores e colaboradores, como também das diretorias da ABEn". A REBEn é financiada com recursos do Programa de Apoio a Publicações Cientificas do MCT, CNPq e FINEP.

\section{Boletim Informativo (BI)}

É o outro órgão oficial de divulgação da ABEn, criado em 1958. Seu primeiro número foi publicado em março deste ano. Seu objetivo na época, conforme registro de Maria Rosa Sousa Pinheiro, era "pôr os associados a par das notícias mais significativas sobre a profissão". Ele representa hoje não apenas um informativo de noticias da enfermagem às Seções e aos seus associados, mas evoluiu no objetivo de tornar-se educativo e de maior expressividade. Deu um salto de qualidade no seu projeto gráfico, com diagramação mais moderna e a inclusão do sistema de porte pago e devolução garantida pela ECT. Os conteúdos das matérias publicadas mostram que a enfermagem, por meio do trabalho desenvolvido pela sua entidade, está inserida no contexto geral da sociedade, discutindo os temas especificos da enfermagem e o aspecto geral de sua inserção nas políticas de saúde e nas políticas públicas.

$\mathrm{O}$ BI tem publicação trimestral e é distribuído às Seções Estaduais e Regionais, aos associados, às instituições de ensino, agências de fomento à pesquisa, às entidades de enfermagem e da saúde. 


\section{Catálogos "Informações sobre Pesquisas e Pesquisadores em Enfermagem"}

Com o progresso da pesquisa em enfermagem, a ABEn, por meio do Centro de Estudos e Pesquisas em Enfermagem (CEPEn), publicou, em 1979, o seu primeiro catálogo, contendo todas as informações sobre "pesquisas e pesquisadores em enfermagem". De 1979 a 1995, foram publicados treze volumes, com o constante crescimento dos trabalhos apresentados. Esta publicação possibilita a divulgação do que há de mais recente na investigação da enfermagem brasileira através da Dissertação de Mestrado e Tese de Doutorado ou Livre-Docência. O CEPEn tem procurado manter a regularidade anual de sua publicação.

\section{Acervo do CEPEn}

O CEPEn foi criado no dia 17 de julho de 1971, e consta do banco de teses; seleção, registro e organização de periódicos, biblioteca e documentos relacionados à enfermagem.

\section{Dia Nacional do Enfermeiro}

Instituído no dia 12 de maio de 1938, por força do Decreto-Lei 2956/38, pelo Presidente Getúlio Vargas, em pleno Estado Novo, foi uma homenagem do Estado à Enfermagem, identificada como "sacerdócio, arte e vocação" e não como reconhecimento do seu trabalho. Foi importante porque surge a Semana Brasileira de Enfermagem.

\section{Semana Brasileira de Enfermagem (SBEn)}

Surgiu na Escola de Enfermagem Ana Nery, idealizada por sua diretora, Lais Netto dos Reis, em 1940. Inicialmente era denominada "Semana do Enfermeiro", mais tarde, em 1958, antes de sua oficialização, passou a ser chamada "Semana Brasileira de Enfermagem". Foi instituída pelo Decreto $n^{\circ} 48202$, de 1960, pelo presidente Juscelino Kubitschek, estabelecendo o período de 12 a 20 de maio para o evento.

Inicialmente, as comemorações tinham o objetivo de homenagear os destaques da enfermagem (em particular Florence Nightingale e Ana Nery), divulgar a profissão e permitir a confraternização dos profissionais. Hoje, predominam os eventos científicos políticos e culturais, quando seus espaços são utilizados para debater assuntos referentes à profissão, debater as políticas de saúde, condições de trabalho, divulgar a profissão junto à comunidade, por meio de eventos comunitários e cursos, e informar sobre a produção científica da enfermagem. 


\section{Congresso Brasileiro de Enfermagem (CBEn)}

O I Congresso Nacional de Enfermagem foi realizado em São Paulo, em 1947, criando assim um espaço de grande importância para o desenvolvimento científico da enfermagem, para sua divulgação como profissão, para o recrutamento de associados e para o financiamento da entidade. $O$ primeiro Congresso teve como tema "Elaborar, em conjunto, um programa eficiente de enfermagem, visando o desenvolvimento da profissão num plano elevado". Nestes 70 anos de existência (1926/1996), foram realizados 47 Congressos Brasileiros de Enfermagem, exceto nos anos de 1953 e 1961 porque o Brasil sediou o X Congresso Internacional do CIE e um Latino-Americano do Comitê Internacional Católico de Enfermeiras e Assistentes Médico-Sociais (CICIAMS).

Os Congressos receberam a denominação Nacional até o IX Congresso Nacional de Enfermagem, em 1956. A partir desta data, são identificados como Congresso Brasileiro de Enfermagem, para distinguir do Congresso Nacional (Poder Legislativo no Brasil).

Os CBEn'S têm como objetivo, dentre outros, propiciar o intercâmbio político técnico, científico e cultural entre os militantes da enfermagem dos vários Estados da Federação, entidades nacionais e internacionais desta área e estimular a produção científica, tecnológica e cultural da enfermagem, promover sua divulgação e encaminhar resoluções e recomendações a partir dos problemas debatidos pela categoria nas plenárias.

A partir das resoluções e recomendações dos Congressos, foram implementadas inúmeras ações de enfermagem. Observa-se que por muito tempo as recomendações dos Congressos voltavam-se principalmente para questões internas e dirigidas às escolas, modificando-se a partir da interferência dos movimentos sociais e das novas perspectivas da enfermagem.

Foi realizado um estudo sobre as resoluções e recomendações de 33 Congressos realizados entre 1947 a 1982. Segundo Oliveira, este estudo levou à identificação das principais metas e objetivos trabalhados no período, constituindo-se nos verdadeiros projetos da enfermagem brasileira: ampliação da capacidade de formação profissional da enfermagem; estruturação e regulamentação da enfermagem como profissão; estruturação do serviço de enfermagem nas instituições de saúde; definição e aprovação de um Código de Ética da Enfermagem; aprimoramento da assistência de enfermagem e estruturação da organização profissional da enfermagem no Brasil. Estes projetos foram trabalhados pela $A B E n$ a partir das diretrizes traçadas pelos Congressos. $O 48^{\circ} \mathrm{CBEn}$ será realizado em São Paulo, cujo tema é "A enfermagem, os 70 anos da ABEn e as perspectivas para o próximo milênio", homenageando a entidade (Anexo 2). 


\section{Seminário Nacional de Pesquisa em Enfermagem (SENPE)}

$\mathrm{Na}$ estrutura organizacional da ABEn, destaca-se o Centro de Estudos e Pesquisas em Enfermagem (CEPEn), órgão destinado a promover e a incentivar a pesquisa na área de enfermagem. Como parte de suas atividades o CEPEn deve "promover a realização de encontros, seminários, jornadas e outros tipos de reuniões cientificas a fim de estabelecer o diagnóstico da situação da pesquisa em enfermagem no Pais".

O primeiro SENPE foi realizado em 1979, em Ribeirão Preto, Estado de São Paulo, com o tema "O estado atual da pesquisa no País"'. O seminário tem a finalidade de congregar pesquisadores, enfermeiros ou de outras áreas profissionais, e representantes da comunidade científica para reflexão, análise e discussão sobre a pesquisa em enfermagem e sua inter-relação com a prática.

No período de 1979 a 1995, foram realizados oito SENPE'S; o nono será realizado em 1997, Vitória-ES (Anexo 2).

\section{Encontros Regionais de Enfermagem (ENF'S)}

Os ENF'S são realizados nas diversas regiões, tendo como finalidade aglutinar a enfermagem e discutir questões de interesse regional apontando diretrizes na política de saúde. Este encontro tornou-se um momento oportuno para os profissionais e estudantes de enfermagem discutirem, refletirem e encaminharem propostas visando o enfrentamento constante da enfermagem na saúde.

\section{Medalha Presidencial}

A medalha foi uma doação do Laboratório Johnson \& Johnson do Brasil à $A B E n$, em homenagem às Presidentes. Um medalhão dourado com a insignia da Associação, constando no verso o nome de todas as Presidentes e o período de sua gestão, a ser usado em comemorações solenes e nas sessões de instalação e encerramento dos CBEn's. Na posse da diretoria nacional, o medalhão é passado para a Presidente empossada A primeira Presidente a usá-lo foi Clarice Della Torre Ferrarini (1963).

Em 1995, a diretoria-gestão 1992/1995 fez doação de um novo medalhão em ouro, pois o anterior não tinha mais espaço para escrever os nomes das presidentes. Ele foi entregue na solenidade de instalação do $47^{\circ} \mathrm{CBEn}$, no Estado do Goiás

\section{Emblema da ABEn}

A necessidade de um símbolo que representasse a Associação Brasileira de Enfermagem surgiu, em 1955, da necessidade de homenagear figuras de importância para a enfermagem. Assim foi adotada uma insignia que deveria constar dos diplomas. 
Em 1958, foi criado o "Emblema da ABEn", na gestão da Presidente Maria Rosa de Sousa Pinheiro (1954/1958). Apresentado em sessão solene de abertura do XII Congresso Brasileiro de Enfermagem, passou a constar dos documentos oficiais da entidade.

O emblema é formado de um retângulo azul escuro, tendo no centro a lâmpada de Aladim, o céu em azul e o Cruzeiro do Sul em branco e o rodapé ouro serve de base à sigla da ABEn, em branco.

\section{Galeria das Presidentes}

Memória alusiva a todas as ex-presidentes da ABEn. Anexo 3

\section{Galeria dos Cartazes}

Inaugurada em 1995, é formada pela exposição dos cartazes alusivos aos eventos realizados pela ABEn, Seções Estaduais e Regionais, como também os eventos nacionais e internacionais.

\section{Relações Internacionais}

A Associação buscou ampliar suas relações com a enfermagem internacional em 1929, quando solicitou sua filiação ao CIE. Isto aconteceu, entretanto, sem que primeiro tivesse sido buscada sua organização interna, no campo político, com a definição de uma política para que a entidade pudesse posicionar-se concretamente diante dos assuntos nacionais e internacionais. A falta desta política leva a entidade a, por muito tempo, abdicar da luta em defesa da categoria, adotando uma prática de colaboração e de legitimação da ação do Estado, que na maioria das vezes estava aliado aos interesses privados defendidos como metas globais no setor da saúde.

A ABEn permanece filiada ao CIE desde 1929. Existe, porém, um grande interesse do COFEN em tornar-se a entidade representativa e filiada ao CIE no Brasil. Se o COFEN conseguir filiar-se, a ABEn será excluida, pois o estatuto do CIE não permite mais que uma entidade nacional nos seus quadros. Em 1955, filiou-se ao Comitê Internacional Católico de Enfermeiras e Assistentes MédicoSociais (CICIAMS), desligando-se em 1986 por determinação estatutária que proibe filiação a qualquer "definição religiosa". Em 1970, filiou-se à Federação Pan-americana dos Profissionais de Enfermagem (FEPPEN). Por meio da FEPPEN, a ABEn participa da "Fundação Ibero-Americana para o Desenvolvimento da Enfermagem (FIDE)". Esta Fundação tem sede fixa na Espanha.

Durante muito tempo a ABEn manteve uma relação com o CIE sem qualquer questionamento sobre suas politicas e suas diretrizes. Nem sempre elas adequam-se à realidade da prática profissional no Brasil $O$ mesmo comportamento teve a ABEn como filiada da FEPPEN, limitando-se a participar das reuniões internacionais e sem nenhum poder de intervenção em suas decisões. 
Segundo Oliveira, a subordinação ao CIE era tal que até mesmo a proposta de elaborar um documento que constasse a política de trabalho da ABEn só foi apresentada em 1971, após o CIE publicar em 1969 sua carta de princípios.

A partir de 1986 processou-se mudanças na postura da ABEn diante destas instituições internacionais. Elas foram inspiradas na busca de autonomia e na defesa da reorganização dos serviços de saúde e da reordenação política e tecnológica da prática de saúde e, em particular, da enfermagem. O Brasil passou, então, a articular-se tanto na América Latina, por meio da FEPPEN, quanto no $\mathrm{CIE}$ para interferir nos seus processos eleitorais.

Em outubro deste ano de 1996, acontecerá, no Brasil, por ocasião do $48^{\circ}$ CBEn, a convenção que elegerá o País-sede da Secretaria Executiva deste organismo. O Brasil, através da ABEn, é candidato a sediar a Secretaria Executiva da FEPPEN.

\section{Lutas - Vitórias - Realizações}

De 1926 a 1976, a ABEn foi a única entidade de enfermagem a lutar pela categoria. Era uma entidade científica e não tinha, portanto, como finalidade, a prática sindical, mesmo que em alguns momentos tenha encaminhado as lutas do enfermeiro neste campo. Para Oliveira, "trabalhou a questão profissional e sindical da enfermagem de forma corporativa, elitista e excludente, restringindose quase que exclusivamente às questões internas da enfermagem,". Não se preocupavam em discutir as políticas de saúde, o que contribuiu para retardar o processo de desenvolvimento global da categoria, limitando seus debates a uma discussão ideológica e emocional, sem aprofundar $O$ aspecto político das questões. Na década de 80 , tem início o processo de mudanças na ABEn $A$ entidade começa a expressar-se como parte da sociedade, encaminhando as lutas da enfermagem no contexto geral das políticas sociais.

\section{Formação}

1. Assessoria na criação das Escolas de Enfermagem que posteriormente se transformaram em Faculdades

2. Assessoria na formulação do currículo mínimo para os cursos dos profissionais de enfermagem.

3. Estruturação e regulamentação da enfermagem como profissão no Brasil.

4. Formação e profissionalização dos militantes da enfermagem, visando diminuir o contingente de práticas.

5. Acompanhamento, discussão e participação na elaboração das leis reguladoras do ensino de enfermagem, até a completa integração com as leis de Diretrizes Básicas da Educação Nacional e a consolidação dos cursos superiores de enfermagem.

6. Assessoria na formulação do currículo mínimo para os cursos dos profissionais de enfermagem. 


\section{Assuntos Profissionais}

1. Elaboração e acompanhamento do anteprojeto que se transformou na Lei $2.604 / 55$, primeira lei que regulamentou o exercício da profissão de enfermagem;

2. Providências para a criação da carreira do enfermeiro e do auxiliar de enfermagem no serviço público, com o enfermeiro ocupando cargo na faixa técnico-científico. Esta luta durou 6 anos, de 1954 a 1960;

3. Elaboração do primeiro Código de Ética para os profissionais de enfermagem;

4. Luta pela Lei $5.905 / 73$, que dispõe sobre a criação dos Conselhos Federal e Regionais de Enfermagem, que durou 28 anos;

5. Levantamento dos recursos e necessidades de Enfermagem no Brasil.

\section{Processo de Democratização da ABEn}

\section{Movimento Participação}

Em 1979, no Congresso Brasileiro de Enfermagem realizado em Fortaleza$\mathrm{CE}$, começa a tomar corpo um movimento de oposição à diretoria então à frente da ABEn. Uma parcela de enfermeiros passa a repensar o papel da entidade. É chamado Movimento Participação, que, para Germano (1993), é um fenômeno social e político, produto do Movimento Geral da Sociedade.

A proposta do Movimento Participação é fundamentada em nova concepção do papel da ABEn, visando uma nova relação da entidade com o Governo e com a sociedade, encampando a luta dos movimentos organizados da sociedade civil, na perspectiva de construção de uma nova sociedade, mais justa e democrática. É também um projeto que busca a construção de uma enfermagem democratizada, tecnicamente qualificada para a sua prática nos serviços de saúde e nas escolas e com competência política para dirigir suas entidades, compreendendo que a enfermagem está coletivamente inserida nas lutas dos profissionais da saúde

O Movimento levou para a entidade exigências de um posicionamento frente ao modelo de assistência de saúde no pais, e passou a oferecer estratégias concretas para mudanças nas políticas de saúde e nas políticas públicas.

\section{Consolidação - mudança da direção política do "movimento participação.}

De 1986 a 1992, a ABEn passou a ser dirigida pelo grupo Participação, possibilitando, assim, a implementação das mudanças propostas. Seguindo as diretrizes políticas que fundamentaram o movimento na sua organização, a ABEn continua sendo o símbolo da profissão, mas não abre mão de compromisso com a vida e a dignidade da assistência que presta à sociedade. 


\section{Desafios da Gestão - 1995/1998}

1. Profissionalização do pessoal de enfermagem sem qualificação, agora ampliado com a incorporação dos agentes comunitários de saúde;

2. Efetiva participação nas instãncias de decisão política e técnica da área de saúde e educação e participação nos Conselhos de Saúde,

3. Luta por melhores salários e condições de trabalho, garantindo aos trabalhadores de enfermagem condições dignas para a sua sobrevivência física, psíquica e intelectual;

4. Fortalecimento de nossas organizações profissionais, responsáveis pela consolidação e expressão da profissão na sociedade;

5. Produção de estudos e pesquisas sistemáticas, objetivando desenvolver e definir meios e padrões tecnológicos apropriados ao atendimento daqueles que demandam nossos serviços;

6. Projeto de classificação da prática de enfermagem em saúde coletiva e o desafio de redefinir as práticas de enfermagem

\section{CONCLUSÃO}

Durante o exercício profissional e de representação da Entidade, sentimos a necessidade premente de sistematizar um histórico em que, de forma clara, objetiva e concisa, pudéssemos mostrar para os profissionais de Enfermagem o que é a $A B E n$ e sua importância para a categoria e, por que não, para os profissionais da saúde.

Nossa pesquisa constatou a existência de grande quantidade de dados sobre a ABEn, que estão, entretanto, dispersos e nem sempre permitem a compreensão do real significado da entidade e de seu papel histórico na luta dos enfermeiros. Neste ano em que a ABEn completa 70 anos, é oportuno organizar um material, compacto, simples e objetivo que retrate esta entidade: suas lutas, vitórias, realizações e o seu papel político na história da enfermagem brasileira. 


\section{SNEXO 1}

ASSOCIAÇÃO BRASILEIRA DE ENFERMAGEM

\begin{tabular}{|c|c|}
\hline SEÇÕES & REGIONAIS \\
\hline ACRE & FEdRA DE SANTANA(BA) \\
\hline ALAGOAS & IPATINGA(MG) \\
\hline AMAZONAS & ITAJUBÁ(MG) \\
\hline BAHIA & JUIZ DE FORA (MG) \\
\hline CEARÁ & MONTES CLAROS (MG) \\
\hline DISTRITO FEDERAL & UBERABA (MG) \\
\hline ESPIRITO SANTO & UBERLÂNDIA (MG ) \\
\hline GOIÁS & NÚCLEO DE BETIM (MG) \\
\hline MARANHÃO & LONDRINA (PR) \\
\hline MATO GROSSO & NITEROI (RJ) \\
\hline MINAS GERAIS & PETROPOLIS(RJ) \\
\hline PARÁ & VOLTA REDONDA (RJ) \\
\hline PARAÍBA & MOSSORO (RN) \\
\hline PARANÁ & CAXIAS DO SUL (RS) \\
\hline PERNAMBUCO & SANTA MARIA (RS ) \\
\hline PIAUÍ & ARARAQUARA(SP) \\
\hline RIO DE JANEIRO & BAURU(SP) \\
\hline RIO GRANDE DO NORTE & BOTUCATU(SP) \\
\hline RIO GRANDE DO SUL & BRAGANÇA PAULISTA (SP) \\
\hline SANTA CATARINA & CAMPINAS (SP) \\
\hline SÃO PAULO & RIBEIRÃO PRETO (SP) \\
\hline \multirow[t]{5}{*}{ SERGIPE } & SANTOS (SP) \\
\hline & SÃO CARLOS(SP) \\
\hline & SÃO JOSÉ DO RIO PRETO (SP) \\
\hline & SOROCABA (SP) \\
\hline & TAUBATÉ(SP) \\
\hline
\end{tabular}



ANEXO 2 - CONGRESSOS BRASILEIROS DE ENFERMAGEM - CBEn'S E SEMI-
NÁRIOS NACIONAIS DE PESQUISA EM ENFERMAGEM - SENPE'S

\begin{tabular}{|c|c|c|c|c|c|}
\hline CONGRESSOS & ANO & LOCAL & SEMINÁRIOS & ANO & LOCAL \\
\hline 1 & 1947 & São Paulo-SP & 1 & 1979 & Ribeirão Preto-SP \\
\hline II & 1948 & Rio de Janeiro-RJ & II & 1982 & Brasília-DF \\
\hline III & 1949 & Rio de Janeiro-RJ & II & 1984 & Florianópolis-SC \\
\hline IV & 1950 & Salvador-BA & IV & 1985 & São Paulo-SP \\
\hline $\mathrm{V}$ & 1951 & Rio de Janeiro-RJ & $\mathrm{V}$ & 1988 & Belothorizonte-MG \\
\hline $\mathrm{VI}$ & 1952 & São Paulo-SP & $\mathrm{VI}$ & 1991 & Rio de Janeiro-RJ \\
\hline VII & 1954 & São Paulo-SP & VII & 1994 & Fortaleza-CE \\
\hline VIII & 1955 & Belo Horizonte-MG & VIII & 1995 & Ribeirão Preto-SP \\
\hline IX & 1956 & Porto Alegre-RS & IX & 1997 & Vitória-ES \\
\hline
\end{tabular}

\begin{tabular}{||c|c|c||}
\hline$X$ & 1957 & Niterói-RJ \\
\hline$X I$ & 1958 & Recife-PE \\
\hline$X I I$ & 1959 & São Paulo-SP \\
\hline XIII & 1960 & Belo Horizonte-MG \\
\hline
\end{tabular}

\begin{tabular}{|c|c|c|}
\hline$X I V$ & 1962 & Curitiba-PR \\
\hline$X V$ & 1963 & Fortaleza-CE \\
\hline$X V I$ & 1964 & Salvador-BA \\
\hline
\end{tabular}

\begin{tabular}{||c|c|c||}
\hline$X V I I$ & 1965 & Rio de Janeiro-RJ \\
\hline$X V I I I$ & 1966 & Belém-PA \\
\hline$X I X$ & 1967 & Brasília-DF \\
\hline$X X$ & 1968 & Recife-PE \\
\hline$X X I$
\end{tabular}

\begin{tabular}{||c|c|c||}
\hline$X X I$ & 1969 & Porto Alegre-RS \\
\hline$X X I I$ & 1970 & São Paulo-SP \\
\hline XXIII & 1971 & Manaus-AM \\
\hline XXIV & 1972 & Belo Horizonte-MG \\
\hline XXV
\end{tabular}

\begin{tabular}{||c|c|c|}
\hline$X X V$ & 1973 & São Paulo-SP \\
\hline$X X V I$ & 1974 & Curitiba-PR \\
\hline$X X V I I$ & 1975 & Salvador-BA \\
\hline
\end{tabular}

\begin{tabular}{|l|l|l}
\hline$X X V I I I$ & 1976 & Rio de Janeiro-RJ \\
\hline$X X I X$ & 1977 & Floranopls-SC \\
\hline
\end{tabular}

\begin{tabular}{|c|c|c|}
\hline$X X I X$ & 1977 & Florianópolis-SC \\
\hline$X X X$ & 1978 & Belém-PA \\
\hline$X X X I$ & 1979 & Fortaleza-CE \\
\hline$X X X \mid$ & 1980 & Brália-DF \\
\hline
\end{tabular}

\begin{tabular}{|c|c|c|}
\hline XXXII & 1980 & Brasília-DF \\
\hline XXXIII & 1981 & Manaus-AM \\
\hline XXXIV & 1982 & Porto Alegre-Rs \\
\hline $\mathrm{XXXV}$ & 1983 & São Paulo-SP \\
\hline XXXVI & 1984 & Belo Horizonte-MG \\
\hline XXXVII & 1985 & Recife-PE \\
\hline XXXVIII & 1986 & Rio de Janeiro-RJ \\
\hline XXXIX & 1987 & Salvador-BA \\
\hline $40^{\circ}$ & 1988 & Belém-PA \\
\hline $41^{\circ}$ & 1989 & Florianópolis-SC \\
\hline $42^{\circ}$ & 1990 & Natal-RN \\
\hline $43^{\circ}$ & 1991 & Curitiba-PA \\
\hline $44^{\circ}$ & 1992 & Brasília-DF \\
\hline $45^{\circ}$ & 1993 & Recife-PE \\
\hline $46^{\circ}$ & 1994 & Porto Alegre-RS \\
\hline $47^{\circ}$ & 1995 & Goiânia-GO \\
\hline $48^{\circ}\left(^{*}\right)$ & 1996 & São Paulo-SP \\
\hline $49^{\circ}$ & 1997 & Belo Horizonte - MG \\
\hline
\end{tabular}


ANEXO 3 - PRESIDENTES DA ABEn NACIONAL

\begin{tabular}{|c|c|c|}
\hline - & EDITH DE MAGALHÃES FRAENKEL & $\begin{array}{c}1927 / 1938 \\
1941 / 1943 \\
1948 / 1950\end{array}$ \\
\hline - & HILDA ANNA KRISCH & $1938 / 1941$ \\
\hline • & ZAÍRA CINTRA VIDAL & $1943 / 1947$ \\
\hline$\bullet$ & MARINA BANDEIRA DE OLIVEIRA & $1947 / 1948$ \\
\hline • & WALESKA PAIXÃO & $1950 / 1952$ \\
\hline • & GLETE DE ALCÂNTARA & $1952 / 1954$ \\
\hline • & MARIA ROSA SOUSA PINHEIRO & $1954 / 1958$ \\
\hline$\bullet$ & MARINA DE ANDRADE RESENDE & $1958 / 1962$ \\
\hline$\bullet$ & CLARICE DELLA TORRE FERRARINI & $1962 / 1964$ \\
\hline • & CIRCE DE MELO RIBEIRO & $\begin{array}{l}1964 / 1968 \\
1980 / 1984\end{array}$ \\
\hline$\bullet$ & AMÁLIA CORREAA DE CARVALIO & $1968 / 1972$ \\
\hline - & GLETE DE ALCÂNTARA & $1972 / 1974$ \\
\hline • & MARIA DA GRAÇA SIMŐES CORTE IMPERIAL & $1974 / 1976$ \\
\hline$\bullet$ & IEDA BARREIRA E CASTRO & $1976 / 1980$ \\
\hline - & MARIA IVETE RIBEIRO DE OLIVEIRA & $1984 / 1986$ \\
\hline - & MARIA JOSÉ DOS SANTOS ROSSI & $1986 / 1989$ \\
\hline$\bullet$ & STELLA MARIA PEREIRA FERNANDES DE BARROS & $1989 / 1992$ \\
\hline - & MARIA AUXILIADORA CÓRDOVA CHRISTÓFARO & $1992 / 1995$ \\
\hline - & MARIA GORETTI DAVID LOPES & $1995 / 1998$ \\
\hline
\end{tabular}




\section{REFERÊNCIAS BIBLIOGRÁFICAS}

1. ASSOCIAÇÃO BRASILEIRA DE ENFERMAGEM. Anais do $8^{\circ}$ Seminário Nacional de Pesquisa em Enfermagem. Ribeirão Preto, 1995. p. $192-$ 196.

2. Livro de Atas da Assembléia Nacional de Delegados, volume V, $\mathrm{VI}, \mathrm{VII}$ e XI.

3. Relatório de Atividades: gestão 1986/1989, 1989/1992, 1992/1995

4. CARVALHO, Anayde Corrêa. Associação Brasileira de Enfermagem: 1926/1976. Documentário. Brasília: 1976.

6. GEOVANINI, Telma; MOREIRA, Almerinda; DORNELLES, Soraia; MACHADO, C. A. Wilian. História da Enfermagem: versões e interpretações, ed. Revinter, 1995

7. OLIVEIRA, Francisca Valda Silva de. Associação Brasileira de Enfermagem. mudança e continuidades - a propósito do movimento participação (1979/1989). Natal, 1990. R. Bras. de Enferm., jul./ago./set. 1995, p. 193. 